\title{
Extraction of Hemicellulosic Sugar and Acetic Acid from Different Wood Species with Pressurized Dilute Acid Pretreatment ${ }^{1}$
}

\author{
Byung-Hwan $\mathrm{Um}^{2 \dagger} \cdot$ Seong-Jik Park ${ }^{3}$
}

\begin{abstract}
Extraction is a necessary element in the bioconversion of lignocellulosics to fuels and chemicals. Although various forms of chemical pretreatment of cellulosic materials have been proposed, their effectiveness varies depending on the treatment conditions and substrate. In this study, mixed hardwood (MH) and loblolly pine (LP) were pretreated with dilute acid in a $100 \mathrm{~mL}$ accelerated solvent extraction (ASE) at the predetermined optimal conditions: temperature: $170^{\circ} \mathrm{C}$, acid concentration: $0.5 \%(\mathrm{w} / \mathrm{v})$, and reaction time: $2 \sim 64 \mathrm{~min}$. This method was highly effective for extracting the hemicellulose fraction. Total xmg (defined as the sum of xylose, mannose, and galactose) can be extracted from milled MH and LP through pressurized dilute acid treatment in maximum yields of $12.6 \mathrm{~g} / \mathrm{L}$ and $15.3 \mathrm{~g} / \mathrm{L}$, respectively, representing $60.5 \%$ and $70.4 \%$ of the maximum possible yields, respectively. The crystallinity index increased upon pretreatment, reflecting the removal of the amorphous portion of biomass. The crystalline structure of the cellulose in the biomass, however, was not changed by the ASE extraction process.
\end{abstract}

Keywords : Acetic acid, Crystallinity, Hemicellulose, Dilute acid extraction, Accelerated solvent extraction (ASE)

\section{INTRODUCTION}

In recent years, the extraction of hemicelluloses from wood has attracted increasing attention, mainly because of the interest in ethanol production during mechanical pulping (Um 2012; Liu and Amidon 2007; Ragauskas et al. 2006). Hemicelluloses are heteropolymers of 5and 6-carbon sugars with side chains. Table 1 shows the major hemicellulose constituents to- gether with wood biomass extractives. If one considers cellulose as a one-dimensional polymer, most hemicelluloses are two-dimensional polymers. Hemicellulose oligomers can be partially extracted from hardwood chips through dissolution in water at high temperatures (Amidon et al., 2008; Liu et al., 2006), and xylose or hemicellulose sugars can be fermented to ethanol by microorganisms (Qureshi et al., 2006; Jeffries and Jin, 2004). Hemicellulosic sugars

1 Received February 17, 2014; accepted March 6, 2014

2 Department of Chemical Engineering and Research Center of Chemical Technology, Hankyong National University, Gyeonggi-do 456-749, Korea

3 Department of Bioresources and Rural System Engineering, Hankyong National University, Gyeonggi-do 456-749, Korea

† Corresponding author : Byung-Hwan Um (e-mail: bhum11@hknu.ac.kr) 
Table 1. Major components of hemicelluloses and extractives (Rousseau et al., 2011).

\begin{tabular}{|c|c|c|c|}
\hline & \multirow{2}{*}{ Type } & \multicolumn{2}{|c|}{ Distribution (wt\%) } \\
\hline & & Softwoods & Hardwoods \\
\hline \multicolumn{2}{|l|}{ Hemicelluloses } & $25 \sim 30$ & $25 \sim 35$ \\
\hline \multicolumn{2}{|c|}{ Galactoglucomannan $(1: 1: 3)$} & $5 \sim 8$ & 0 \\
\hline \multicolumn{2}{|c|}{ (Galacto) glucomannan $(0.1: 1: 4)$} & $10 \sim 15$ & 0 \\
\hline \multicolumn{2}{|l|}{ Glucomannan $(1: 2-1: 1)$} & 0 & $2 \sim 5$ \\
\hline \multicolumn{2}{|l|}{ Arabinoglucuronoxylan } & $7 \sim 10$ & Trace \\
\hline \multicolumn{2}{|l|}{ Glucuronoxylan } & Trace & $15 \sim 30$ \\
\hline \multicolumn{2}{|l|}{ Extractives } & $5 \sim 8$ & $2 \sim 4$ \\
\hline Aliphatic and alicyclic & \multicolumn{3}{|c|}{ Terpenes: terpenoids, esters, fatty acids, alcohols } \\
\hline Phenolics & \multicolumn{3}{|c|}{ Phenols: stilbenes, lignans, isoflavones } \\
\hline Carbohydrates & \multicolumn{3}{|c|}{ Arabinose, galactose, glucose, xylose, raffinose, starch, pectic material } \\
\hline Inorganics & \multicolumn{3}{|l|}{$\mathrm{Ca}, \mathrm{K}, \mathrm{Mg}, \mathrm{Na}, \mathrm{Fe}, \mathrm{SO}_{4}{ }^{2}-\mathrm{Cl}^{-}$} \\
\hline Others & \multicolumn{3}{|l|}{ Cyclitols tropolones, amino } \\
\hline \multicolumn{2}{|l|}{ Ash } & $0.2 \sim 0.5$ & $0.2 \sim 0.8$ \\
\hline
\end{tabular}

may also be used as building blocks for biodegradable plastics (Keenan et al., 2004) or other products and chemicals that are currently made from petroleum (Liu et al., 2006). The residual woodchips can be processed into pulp to make paper, burned as a renewable energy source, or converted to reconstituted wood products such as fiberboard or pellets (Amidon, 2006; Amidon and Liu, 2009). This process would add additional products to the current paper and wood energy business, triggering evolution toward wood-based biorefineries (Myerly et al., 1981). The production of pulp and/or paper products from cellulose remains attractive today because cellulose has a higher value as a pulp than as a sugar. However, the pulp and paper industry in the United States and Canada has actually been declining steadily in recent years as production shifts to higher growth areas such as China and Brazil. Further conversion of cellulose into sugars and/or other chemicals/liquid fuel is highly desirable because of the higher future demand predicted. A purpose-built biorefinery would include all these process alternatives, though adaptations of current processing locations may not include all the alternatives.

More recently, much research has been carried out on xylose dissolved in pulp and on biorefinery; since xylan is the main component of hardwood hemicelluloses, xylooligomers and xylose are the main products obtained through hydrothermal treatments of this raw material. Sugar-degradation products (such as furfural or hydroxymethylfurfural) and acetic acid (generated from acetyl groups) can also appear in the reaction media. Extraction and subsequent acid hydrolysis are commonly performed in water media. There are many advantages of using water as the sole solvent. However, harsh reaction conditions, that is, either a high temperature or a combination of high temperature and strong acid, are required, and thus the processes are limited to large-scale operations for economic 


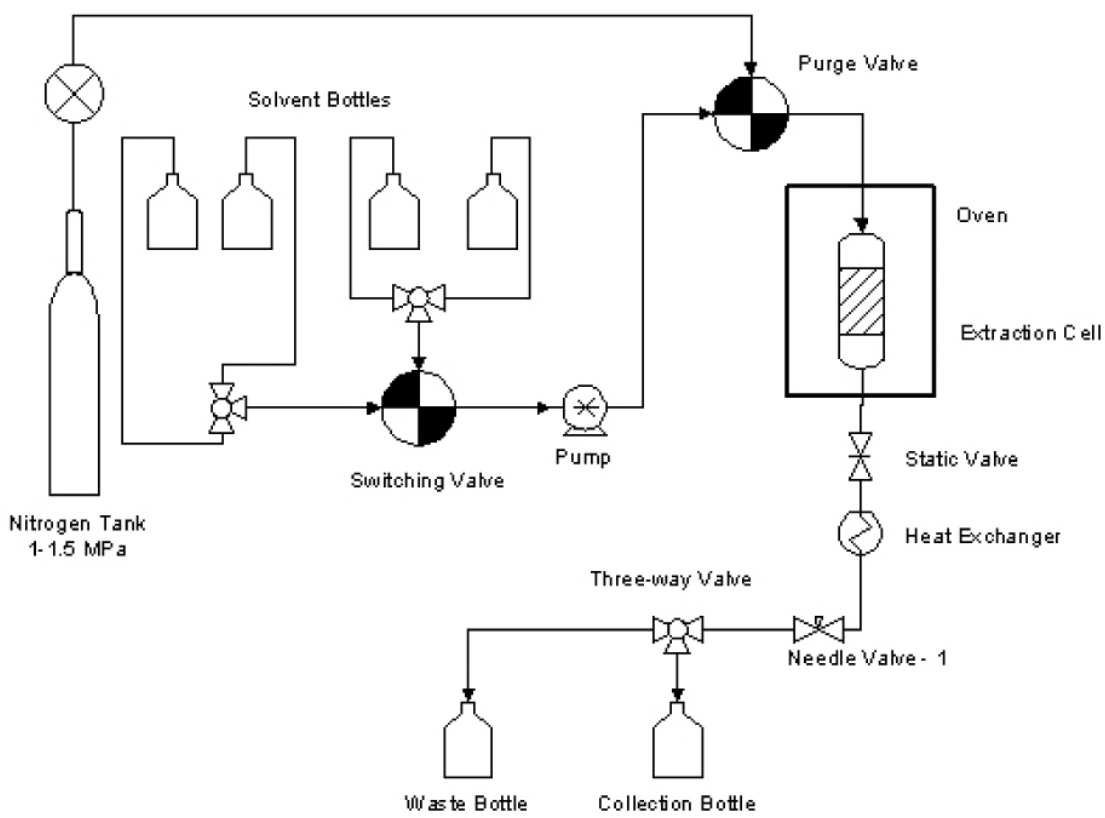

Fig. 1. Schematic diagram of ASE 300 (Accelerated Solvent Extractor).

success. With the aim of achieving the complete fractionation of wood into hemicelluloses, lignin, and cellulose, Li et al. (2005) suggested steam-explosion treatment, in which autohydrolysis is the main reaction. Most of these studies were focused on hardwoods, because this type of biomass is under-utilized in many countries, but also because hardwoods are easier to fractionate by autohydrolysis. The extraction of hemicelluloses from hardwoods prior to kraft pulping has also been studied recently (Park et al., 2013; Karlsson et al., 2006; van Heiningen 2006; Leschinsky et al., 2007).

The objective of this study was to assess and compare the compositions of hemicellulose extracts obtained under an extraction temperature of $170^{\circ} \mathrm{C}$, with a dilute acid concentration of $0.5 \%(\mathrm{w} / \mathrm{v})$, and with various solid-to-liquid ratios using hardwood (mixed hardwood) and softwood (loblolly pine). Experiments were also carried out to investigate the extent of changes in chemical composition as a function of cellulose crystallinity.

\section{MATERIALS AND METHODS}

\subsection{Raw Material}

Mixed hardwood and loblolly pine (Pinus taeda) chips were used throughout this study, and were supplied by the Old Town Fuel \& Fiber Kraft Pulp Mill in Old Town, ME. The hardwood chips consisted of roughly $50 \%$ maple, with the remainder being mostly beech and poplar. The chips were milled with a granulator (MDS 120/150 granulators, Hellweg Maschinenbau $\mathrm{GmbH} \&$ Co. KG, Roetgen, Germany) equipped with a 2-mm rejection screen. The milled materials were further separated to give an average size of $30 \sim 40$ mesh $(0.595 \sim 0.420$ 
$\mathrm{mm}$ ) by using a portable USA standard Sieve (Tyler Industrial products, Mentor, $\mathrm{OH}$ ) for determination of the total solids/moisture ratio and for carbohydrate content analysis.

\subsection{Equipment and Pretreatment Procedure}

Fig. 1 shows a schematic diagram of an accelerated solvent extraction (ASE) system. The ASE 300 was purchased from Dionex Corporation. For this study we used Dionium ${ }^{\circledR} 100 \mathrm{~mL}$ reactor cells, which are manufactured to be resistant to corrosion by dilute acid. Sulfuric acid was used as the catalyst, and was diluted to a working solution of $0.5 \%(\mathrm{w} / \mathrm{v})$. Air-dried wood mills $(1$ or $10 \mathrm{~g})$ were packed into a $100 \mathrm{~mL}$ Dionium cell. Room-temperature acid solution was pumped into the cell when already in the oven, and was allowed to equilibrate with the oven temperature $\left(170^{\circ} \mathrm{C}\right)$. We used a constantpressure mode, which maintained a pressure of $1,500 \mathrm{psi}$ in the cell. The cell was held at static temperature and pressure for the desired reaction time, and then evacuated into the 250 $\mathrm{mL}$ collection vessel. The cell was flushed with one reactor volume of the acid solution and then purged with nitrogen for 30 s. The cell was then flushed with four reactor volumes of deionized (DI) water to remove any excess hydrolyzed sugars in the cell and quench the hydrolysis reaction. Table 2 presents an outline of the extraction conditions investigated in the experiments.

\subsection{Analysis of Extract Solutions}

The sugar composition of the reaction products was analyzed quantitatively by HPLC. The
Table 2. Values of parameters used in ASE 300 runs

\begin{tabular}{cc}
\hline Parameters & Values \\
\hline \hline Temperature & $170^{\circ} \mathrm{C}$ \\
Acid concentration & $0.5 \%(\mathrm{w} / \mathrm{v}) \mathrm{H}_{2} \mathrm{SO}_{4}$ \\
Particle size & $<2 \mathrm{~mm}$ \\
Residence time & $2 \sim 64 \mathrm{~min}$ \\
Substrate & Mixed hardwood and loblolly pine \\
\hline
\end{tabular}

Shimadzu model (LC-10AT Liquid Chromatogram, Shimadzu Corp., Kyoto, Japan) HPLC used for carbohydrates measurement had BioRad Aminex HPX-87H $(300 \times 7.8 \mathrm{~mm})$ and a Cation $\mathrm{H}$ micro-guard cartridge $(30 \times 4.6 \mathrm{~mm})$ (Bio-Rad Laboratories Inc., Hercules, CA). The column was maintained at $60^{\circ} \mathrm{C}$, and $5 \mathrm{mM}$ $\mathrm{H}_{2} \mathrm{SO}_{4}$ was used as eluent at a flow rate of 0.6 $\mathrm{mL} / \mathrm{min}$. All the sugar peaks were detected with a refractive index (RI) detector and UV absorption $(280 \mathrm{~nm})$, and were identified and quanti-fied through comparison with the retention times of authentic standards. The Bio-Rad Aminex HPX-87H analytical column allows concurrent analysis of sugars, small-chain organic acids, and sugar degradation products, but does not distinguish between the sugars xylose, mannose, and galactose, which are therefore reported as the aggregate xmg. A previous study showed that the quantification of total sugars in Green Liquor extracts is as effective with the HPX$87 \mathrm{H}$ column as with other methods that are capable of differentiating all of the sugars present (Um and van Walsum, 2010).

\subsection{X-ray Diffraction Analysis}

The crystallinities of untreated and treated wood chips were measured at the XRD Laboratory, AWEC, University of Maine with a Rigaku 
Table 3. Chemical composition of hardwood and softwood on dry basis

\begin{tabular}{lcc}
\hline \multicolumn{1}{c}{ Components } & $\begin{array}{c}\mathrm{MH}^{\mathrm{a}} \\
\text { dry solids }(\%, w / w)\end{array}$ & $\begin{array}{c}\text { LP }^{\mathrm{b}} \\
\text { dry solids }(\%, w / w)\end{array}$ \\
\hline \hline As fermentable sugars (theoretical yield) & & \\
Glucose & 46.8 & 44.1 \\
Xylose+mannose+galactose & $\underline{25.5}$ & $\underline{22.2}$ \\
Subtotal & 72.3 & 66.3 \\
As major constituents of substrates & & \\
Cellulose & 42.1 & 39.7 \\
XMG $^{\mathrm{c}}$ & 22.4 & 19.5 \\
Arabinan & 2.3 & 2.0 \\
Acetyl & 3.6 & 1.8 \\
Uronic acid & 2.2 & 1.9 \\
Klason lignin & 23.4 & 27.2 \\
Extractives & 2.6 & 3.9 \\
Ash & 0.3 & 0.6 \\
Others & $\underline{1.1}$ & 3.4 \\
Subtotal & 100.0 & 100.0 \\
\hline
\end{tabular}

${ }^{\mathrm{a}}$ Mixed hardwood

${ }^{\mathrm{b}}$ Loblolly pine

${ }^{\mathrm{c}} \mathrm{XMG}=\mathrm{xylan}+$ mannan + galactan

Powder X-ray Diffractometer (Rigaku Denki Co., Japan). The specimen was scanned at $2 \%$ min from $2 \theta=10^{\circ}$ to $26^{\circ}$ with a step size of $0.05^{\circ}$. The definition of crystallinity index is

$$
\mathrm{CrI}=\left(I_{002}-I_{a m}\right) / I_{002} \times 100
$$

, where $I_{002}$ is the intensity of the diffraction from the 002 plane at $2 \theta=22.6^{\circ}$ and $I_{a m}$ is the intensity of the background scatter measured at $2 \theta \approx 18.7^{\circ}$ (Segal et al., 1959).

\section{RESULTS AND DISCUSSION}

\subsection{Chemical Composition of Raw Material}

The chemical composition of loblolly pine was determined according to NREL Laboratory Analytical Procedures (Sluiter et al., 2008). The component analysis results of rape straw are presented in Table 3. As shown in Table 3, the carbohydrate fractions (cellulose and hemicellulose) of mixed hardwood (MH) and loblolly pine (LP) were determined to be $64.5 \mathrm{wt} \%(42.1$ wt $\%$ glucan, $22.4 \mathrm{wt} \% \mathrm{XMG}$, and $2.3 \mathrm{wt} \%$ arabinan) and $59.2 \mathrm{wt} \%$ (39.7 wt $\%$ glucan, 19.5 wt $\%$ XMG, and $2.0 \mathrm{wt} \%$ arabinan), respectively. Analysis of MH and LP show that theoretical fermentable sugars accounted for more than $72.0 \%$ and $66.0 \%$, respectively, on a dry matter basis. The insoluble lignin (Klason lignin) contents were $23.4 \mathrm{wt} \%$ and $27.2 \mathrm{wt} \%$, respectively, and only small amounts of extractives $(\mathrm{MP}=3.52 \pm 0.12 \mathrm{wt} \%, \mathrm{LP}=3.52 \pm 0.12$ 
wt $\%$ ) were detected. Acetyl in MP and LP accounted for $3.6 \%$ and $1.8 \%$ respectively, and uronic acid was amounted to $2.2 \%$ and $1.9 \%$, respectively. The results are in agreement with previous reports on the composition of woody biomass (Um and van Walsum, 2010; Frederick et al., 2008).

\subsection{Total Solid Recovery and $\mathrm{pH}$ Change in Hydrolyzate}

For the evaluation of the efficiency of dilute acid as a pretreatment for MH and LP, the solid yield was calculated in relation to the raw material. Fig. 2 shows the trend of solid yield and $\mathrm{pH}$ in the hydrolyzate. For $1 \%$ solid loading, the solid yields ranged from $42.4 \%$ to $62.1 \%$ (MP) and from $55.8 \%$ to $68.7 \%$ (LP), with average values of $60.4 \%$ and $69.3 \%$, respectively, of the initial dry weight. Meanwhile, a lower solid recovery for $10 \%$ solid loading was determined after pretreatment under the same severities. As expected, owing to the enhanced effect on the removal of water-soluble components, the overall solubilization of woody biomass increased under harsher conditions, which is consistent with the trend reported in the literature (Kobayashi et al., 2009; Pérez et al., 2007).

Fig. 2 shows the $\mathrm{pH}$ of the hydrolyzates as a function of reaction time for the extraction experiments. For dilute acid extractions at $0.5 \%$ $(\mathrm{w} / \mathrm{v})$, the $\mathrm{pH}$ of the final extraction liquor increases slightly above 1.5 . The results thus obtained show that higher severity increase the $\mathrm{pH}$ further, indicating more complete consumption of the added dilute acid chemicals followed by an increase in acetic acid release from hemicellulose.

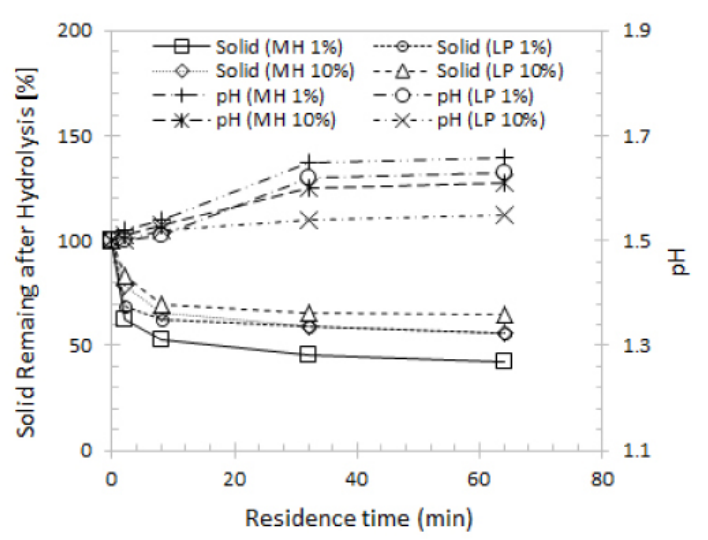

Fig. 2. Percent of solid remaining and $\mathrm{pH}$ change in the hydrolyzate after dilute acid extraction as a function of residence time

\subsection{Sugar and Acetic Acid Content in Hydrolyzate}

Extracts of hemicelluloses and oligosaccharides were analyzed immediately after dilute acid extraction. The hemicellulosic sugars, formed by hydrolysis during extraction, were determined by NREL standard analytical procedures (Sluiter et al., 2006). All results for the extraction of milled woods are presented in Figure 3 as function of reaction time and solid loading percent. The maximum yield of xmg of 12.6 $\mathrm{g} / \mathrm{L}$ for MP was found under conditions of $10 \%$ solid loading for $8 \mathrm{~min}$ at $170^{\circ} \mathrm{C}$, and a yield of slightly over $15.0 \mathrm{~g} / \mathrm{L}$ was obtained for LP, which represents $70.1 \%$ of the available $\mathrm{xmg}$ (Fig. 3b). The xmg yields dropped clearly for MP and LP after 8 and $32 \mathrm{~min}$, respectively, at $170^{\circ} \mathrm{C}$. The decrease was most extensive for $\mathrm{xmg}$, probably because of acidic degradation, mainly of furfural (Lai, 2001). The yields of galactoglucomannan-based sugars also decreased slightly. The decreased yield of galactoglucomannan is probably related to the hydrolysis of 

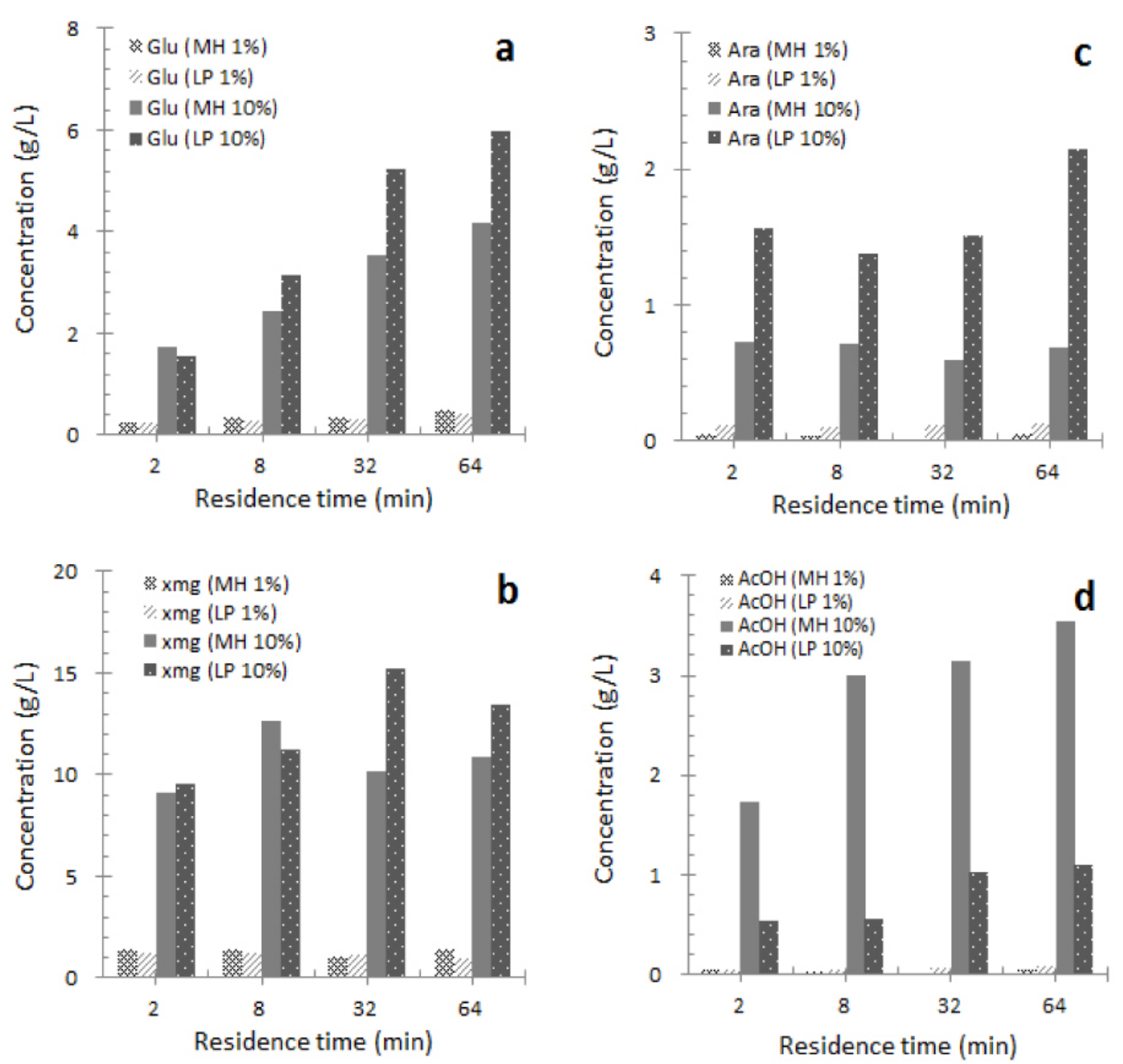

Fig. 3. (a) Sugars (glucose, xmg, and arabinose) and acetic acid yields from dilute acid extraction of MP and LP as a function of solid loading and residence time: (a) glucose, (b) xmg, (c) arabinose, and (d) acetic acid.

acetyl groups, leading to the lower water solubility of galactoglucomannan. Meanwhile, a sugar yield increase was observed for glucose under the reaction conditions employed (Fig. 3a). This may be explained by the low-solubility cellulose, which is probably partially degraded under the dilute acid conditions applied. The relatively few arabinose units in the extracts are probably derived mainly from arabinogalactans, which are minor water-soluble pol- ysaccharides that also occur in wood.

Both free and esterified acetic acid in the extracts were analyzed by HPLC. The amount of free acetic acid increased with reaction time (Fig. 3d). The degree of acetylation was calculated by considering the number of mannose units in the extracts, with the assumption that all acetyl groups are on the mannose units, as documented to be the case for galactoglucomannan released from thermomechanical pulp (TMP) 


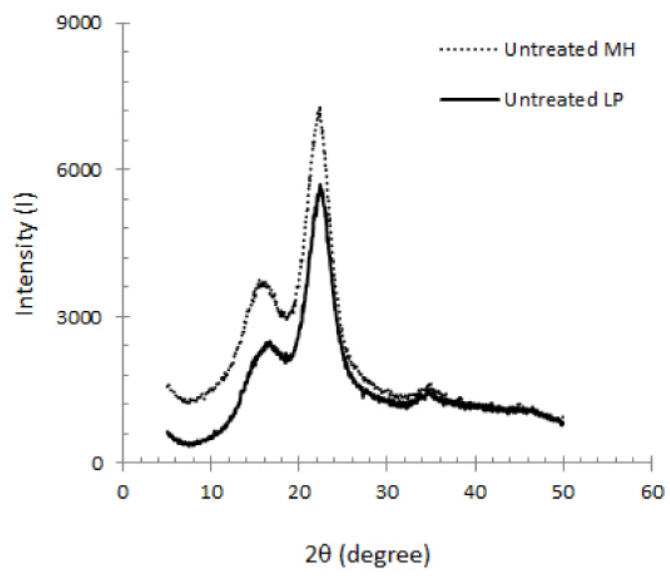

Fig. 4. XRD patterns of untreated MP and LP.
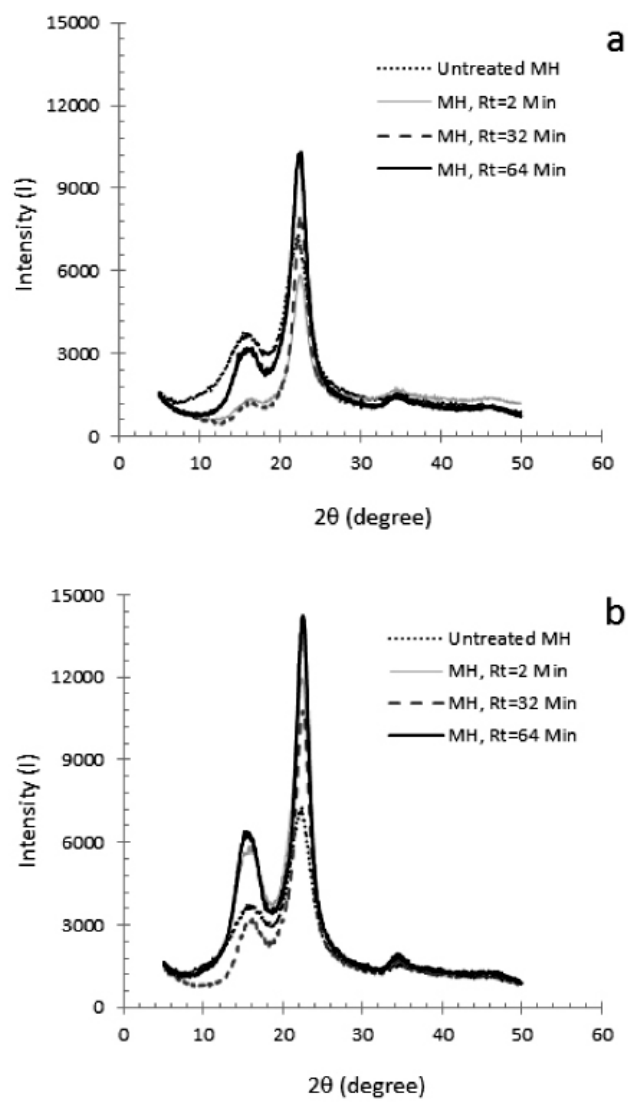

(Hannuksela, 2004). As expected, we also found that acetic acid derived from $\mathrm{MH}$ release increased proportionally with reaction time. In addition, as expected, less release of acetic acid was detected for LP over the whole reaction time. The acetate formation of MP appears to peak at a temperature of $170^{\circ} \mathrm{C}$ and reaction time of $64 \mathrm{~min}$. However, essentially, all acetyl groups were hydrolyzed from the dissolved galactoglucomannan. A high degree of acetylation is necessary for good water solubility, and accordingly, for a high extraction yield of high-molar-mass galactoglucomannan.
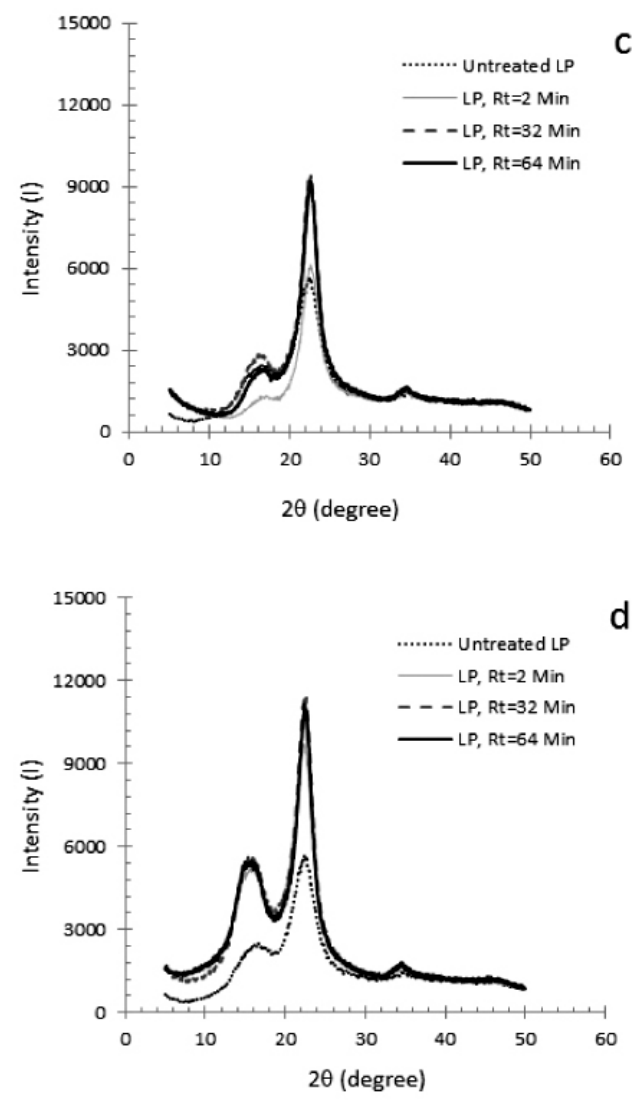

Fig. 5. Comparison of XRD profiles with untreated and extracted samples as a function of reaction time. Note: (a), (c) $1 \%(w / w)$ solid loading and (b), (d) $10 \%(w / w)$ solid loading. 

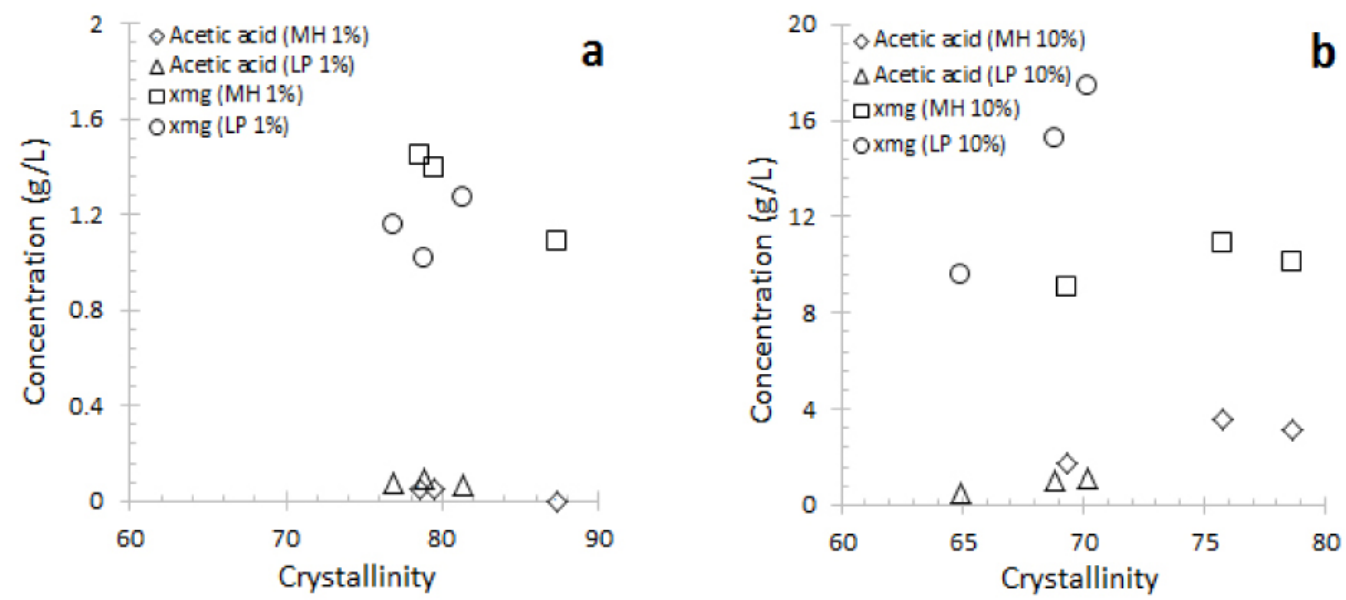

Fig. 6. Effect of CrI (Crystallinity Index) on extraction yield in ASE. Note: ASE extraction conditions: $0.5 \%$ $(\mathrm{w} / \mathrm{v})$ sulfuric acid, $170^{\circ} \mathrm{C}, 2 \sim 64 \mathrm{~min}$.

\subsection{Crystallinity and Hemicellulose Extraction}

The physical properties and cellulose microstructure are among the factors potentially influencing enzymatic hydrolysis and fermentation processes. One frequently cited property is biomass crystallinity. We measured the X-ray diffraction patterns of treated and untreated biomass as a function of treatment time (Figs. 4 and 5), from which the crystallinity indexes were determined. The diffraction patterns show that the CrI values of $\mathrm{MH}$ and LP actually increase with ASE treatment time (Fig. 5). The $\mathrm{CrI}$ of treated milled wood chips as a function of extraction yield is shown in Fig. 6. The CrI is strongly influenced by biomass composition, but it is found that the yield of acetic acid is not affected significantly by the CrI. For lignocellulosic biomass, the crystallinity index measures the relative amount of crystalline cellulose in the total solid. ASE dilute acid treatment mainly removes xylan, which is amorphous, so the CrI value increases after ASE extraction.
An increased $\mathrm{CrI}$ after biomass pretreatment has been observed in many previous investigations (Kasahara et al., 2001; Chang and Holtzapple, 2000; Tanahashi et al., 1983). It is uncertain, however, whether the cellulose structure in MP and LP is altered by the ASE treatment. In the XRD of Fig. 5, the peak height of the MP and LP increases approximately in proportion with the cellulose content of the biomass. This indicates that the increased CrI upon ASE treatment is caused primarily by the removal of amorphous substances (lignin and hemicellulose), and is not due to changes in the basic crystalline structure of the cellulose. The results agree with the findings of Puri (1984), who reported that the crystallinity of cellulose in various lignocellulosic materials remains unchanged irrespective of the structural changes caused by several pretreatments.

\section{CONCLUSIONS}

Hemicellulosic sugars, which contain a major part of their acetyl groups, can be extracted 
from milled $\mathrm{MH}$ and LP through pressurized dilute acid treatment in maximum yields of 12.6 $\mathrm{g} / \mathrm{L}$ and $15.3 \mathrm{~g} / \mathrm{L}$, respectively, representing $60.5 \%$ and $70.4 \%$ of the maximum possible yields, respectively. Such xmg yields can be obtained through batch extraction of milled wood at temperatures of $170^{\circ} \mathrm{C}$ with extraction times ranging from 8 to $32 \mathrm{~min}$. Longer extraction times would lead to a slightly higher $\mathrm{pH}$ because of the deacetylation of galactoglucomannan, and consequently, the solubility of $\mathrm{xmg}$ and its yield would decrease. The severe reaction conditions might also be caused partly by the uronic acids released into the water phase from pectins and xylans. Other major compound groups in the extracts are lignin and acetic acid. The CrI of woody biomass rises after ASE extraction mainly because of the removal of amorphous substances. It could not be found that the crystalline structure of the glucan content of the biomass is changed because of the ASE extraction process.

\section{ACKNOWLEDGEMENTS}

This work was supported financially by a National Research Foundation of Korea (NRF) grant funded by the Korea government (MEST), Project No. 2012R1A1A1003107.

\section{REFERENCES}

1. Amidon, T. 2006. The biorefinery in New York: Woody biomass into commercial ethanol. Pulp and Paper Canada, 107: 47 50.

2. Amidon, T. and Liu, S. 2009. Water-based woody biorefinery. Biotechnology advances, 27 : $542 \sim 550$.

3. Amidon, T., Wood, C., Shupe, A., Wang, Y., Graves, M., and Liu, S. 2008. Biorefinery: Conversion of woody biomass to chemicals, energy and materials. Journal of Biobased Materials and
Bioenergy, 2: $100 \sim 120$.

4. Chang, V. S. and Holtzapple, M. T. 2000. Fundamental factors affecting biomass enzymatic reactivity. Appl. Biochem. Biotechnol., 84 86, 5 37.

5. Frederick, W. J. Jr., Lien. S. J., Courchene, C. E., DeMartini, N. A., Ragauskas, A. J., and Iisa, K. 2008. Production of ethanol form carbohydrates from loblolly pine: A technical and economic assessment. Bioresource Technology, 99: $5051 \sim 5057$.

6. Hannuksela, T. and Herve, C. 2004. NMR structural determination of dissolved O-acetylated galactoglucomannan isolated from spruce thermomechanical pulp. Carbohydr. Res., 339: 301 312.

7. Jeffries, T. and Jin, Y. 2004. Metabolic engineering for improved fermentation of pentoses by yeasts. Applied Microbiology and Biotechnology, 63: $495 \sim 509$.

8. Karlsson, P., Roubroeks, J. P., Glasser, W. G., and Gatenholm, P. 2006. Optimization of the process conditions for the extraction of heteropolysaccharides from birch (Betula pendula). In: Feedstocks for the Future. ACS Symp., Series 921, pp. 321 333 .

9. Kasahara, K., Sasaki, H., Donkai, N., Yoshihara, T., and Takagishi, T. 2001. Modification of trencel with treatment of ferric sodium tartrate complex solution. I. Effect of treatment condition. Cellulose, 8: $23 \sim 28$.

10. Keenan, T., Tanenbaum, S., Stipanovic, A., and Nakas, J. 2004. Production and characterization of poly-beta-hydroxyalkanoate copolymers from Burkholderia cepacia utilizing xylose and levulinic Acid. Biotechnology Progress, 20: 1697 1704.

11. Kobayashi, N., Okada, N., Hirakawa, A., Sato, T., Kobayashi, J., Hatano, S., Itaya, Y., and Mori, S. 2009. Characteristics of solid residues obtained from hot-compressed-water treatment of woody biomass. Ind. Eng. Chem. Res., 48(1): $373 \sim 379$.

12. Lai, Y. Z. 2001. Chemical degradation. In: Wood 
and Cellulose Chemistry. Eds. Hon, D.N.-S., Shiraishi, N. Marcel Dekker, pp. $443 \sim 512$, New York.

13. Leschinsky, M., Patt, R., and Sixta, H. 2007. Water prehydrolysis of E. globulus with the main emphasis on the formation of insoluble components. In: Proceeding of the Pulp Paper Conf., Fibre Modifications and Brightening, pp. 7 14, Finnish Paper Engineers Association, Helsinki, Finland.

14. Li, J., Henriksson, G. and Gellerstedt, G. 2005. Carbohydrate reactions during high-temperature steam treatment of aspen wood. Appl. Biochem. Biotechnol., 125: 175 188 .

15. Liu, S., Amidon, T., Francis, R., Ramarao, B., Lai, Y., and Scott, G. 2006. From forest biomass to chemicals and energy. Biorefinery initiative in New York State. Industrial Biotechnology, 2: $113 \sim 120$.

16. Myerly, R., Nicholson, M., Katzen, R., and Taylor, J. 1981. The forest refinery. Chemtech, 11: $186 \sim 192$.

17. Park, S.J., Moon, J.K., and Um, B.H. 2013. Evalulation of the Efficiency of Solvent Systems to Remove Acetic Acid Derived from PrePulping Extraction. J. Korean Wood Sci. \& Tech., 41(5): 447 455 .

18. Perez, J. A., Gonzalez, A., Oliva, J. M., Ballesteros, I., and Manzanares, P. 2007. Effect of process variables on liquid hot water pretreatment of wheat straw for bioconversion to fuel-ethanol in a batch reactor. J. Chem. Technol. Biotechnol. 82(10): $929 \sim 938$.

19. Puri, V. P. 1984. Effect of crystallinity and degree of polymerization of cellulose on enzymatic saccharification. Biotechnol. Bioeng., 26: 1219 1222.

20. Qureshi, N., Dien, B., Nichols, N., Saha, B., and Cotta, M. 2006. Genetically engineered Escherichia coli for ethanol production from xylose substrate and product inhibition and kinetic parameters. Food and Bioproducts Processing 84: 114 122.
21. Ragauskas, A. J., Nagy, M., Kim, D. H., Eckert, C. A., Hallett, J. P., and Liotta, C.L. 2007. From wood to fuels: integrating biofuels and pulp production. Ind. Biotechnol, 2: 55 65.

22. Rousseau, R., Hawkes, J., and Liu, S. 2011. Growing systems for traditional and new forest-based materials, in the Plant Biomass Conversion, Elizabeth E. H., Peter N. P., and Randall P. Ed., pp. 69, John Wiley \& Sons Ltd, West Sussex, UK.

23. Segal, L., Creely, J. J., Martin, A. E., and Conrad, C. M. 1959. An empirical method for estimating the degree of crystallinity of native cellulose using the X-ray diffractometer. Textile Res. J., 29: $786 \sim 794$.

24. Sluiter, A., Hames, B., Ruiz, R., Scarlata, C., Sluiter, J., and Templeton, D. 2008. Determination of structural carbohydrates and lignin in biomass. National Renewable Energy Laboratory NREL/TP-510-42681 ed. Golden, CO.

25. Sluiter, A., Hames, B., Ruiz, R., Scarlata, C., Sluiter, J., and Templeton, D. 206. Determination of sugars, byproducts, and degradation products in liquid fraction process samples. National Renewable Energy Laboratory NREL/TP-51042623 ed. Golden, CO.

26. Tanahashi, M., Takada, S., Aoki, T., Goto, T., Higuchi, T., and Hanai, S. 1983. Characterization of explosion wood. 1. Structure and physical properties. Wood Res., 69: 36 51.

27. Um, B. H. 2012. Evaluation of Secondary Acid and Enzymatic Hydrolysis of Hemicellulose in Hot Water Pre-Pulping Extract of Mixed Hardwoods. Mokchae Konghak., 40(2): 123 132 .

28. Um, B. H. and van Walsum, G. P. 2010. Mass balance on green liquor pre-pulping extraction of northeast mixed hardwood. Bioresource Technology. 101: $5978 \sim 5987$.

29. van Heiningen, A. 2006. Converting a kraft pulp mill into an integrated forest biorefinery. Pulp Pap. Can. 107: 38 43. 